\title{
Achaete-scute homolog-1 linked to remodeling and preneoplasia of pulmonary epithelium
}

\author{
Xiao-Yang Wang ${ }^{1}$, El Habib Dakir ${ }^{1}$, Xu Naizhen ${ }^{1}$, Sandra M Jensen-Taubman ${ }^{1}$, Francesco J DeMayo² \\ and R Ilona Linnoila ${ }^{1}$
}

The basic helix-loop-helix protein achaete-scute homolog-1 (ASH1) is involved in lung neuroendocrine (NE) differentiation and tumor promotion in SV40 transgenic mice. Constitutive expression of human ASH-1 (hASH1) in mouse lung results in hyperplasia and remodeling that mimics bronchiolization of alveoli (BOA), a potentially premalignant lesion of human lung carcinomas. We now show that this is due to sustained cellular proliferation in terminal bronchioles and resistance to apoptosis. Throughout the airway epithelium the expression of anti-apoptotic Bcl-2 and c-Myb was increased and Akt/mTOR pathway activated. Moreover, the expression of matrix metalloproteases (MMPs) including MMP7 was specifically enhanced at the bronchiolo-alveolar duct junction and BOA suggesting that MMPs play a key role in this microenvironment during remodeling. We also detected MMP7 in 70\% of human BOA lesions. Knockdown of hASH1 gene in human lung cancer cells in vitro suppressed growth by increasing apoptosis. We also show that forced expression of hASH1 in immortalized human bronchial epithelial cells decreases apoptosis. We conclude that the impact of hASH1 is not limited to cells with NE phenotype. Rather, constitutive expression of hASH1 in lung epithelium promotes remodeling through multiple pathways that are commonly activated during lung carcinogenesis. The collective results suggest a novel model of BOA formation via hASH1-induced suppression of the apoptotic pathway. Our study yields a promising new preclinical tool for chemoprevention of peripheral lung carcinomas.

Laboratory Investigation (2007) 87, 527-539; doi:10.1038/labinvest.3700552

KEYWORDS: achaete-scute homolog 1; apoptosis; bronchiolization of alveoli; lung; mouse model; preneoplasia; proliferation

Lung cancer is the leading cause of cancer deaths in both men and women in the United States. The 5-year survival rate has remained low (15\%), because the disease is generally detected at advanced and disseminated stage. ${ }^{1}$ Contributing to the late diagnosis is the fact that precursor lesions for most lung cancer types are poorly understood. We have previously shown that the deletion of achaete-scute homolog-1 (ASH1, ASCL1), a proneural transcription factor, highly expressed in lung neuroendocrine (NE) cancers leads to the absence of pulmonary NE cells (PNECs), potential progenitors for NE cancers. $^{2}$ Constitutive expression of human ASH1 (hASH1) in the airway epithelium, on the other hand, results in epithelial proliferation and metaplasia suggesting a preneoplastic phenotype.

ASH1 belongs to a diverse family of transcriptional regulators involved in fetal development and cancer that utilize the evolutionarily conserved basic helix-loop-helix (bHLH) motif. ${ }^{3}$ Murine ASH1 (mASH1) plays a critical role in the development of the brain and the diffuse NE system including adrenal medullary chromaffin cells, thyroid parafollicular C cells, glomus chief cells and PNECs, ${ }^{2,4-8}$ potential progenitors for small cell lung cancer (SCLC). During neurogenesis mASH1 expression is confined to mitotically active precursors where it is involved in the early stages of lineage commitment in a cell autonomous fashion. ${ }^{9,10}$ In more mature neurons the expression is extinguished. While achaete-scute complex transcription factors in Drosophila may also induce neuronal fate commitment in undifferentiated ectodermal cells there is no evidence that this happens in vertebrates. In SCLC constitutive, rather than transient expression of human ASH1 (hASH1), promotes proliferation and a potentially more primitive phenotype. ${ }^{2,11}$

To study the impact of hASH1 on lung carcinogenesis, we have made a transgenic mouse with the murine Clara cell

${ }^{1}$ Cell and Cancer Biology Branch, Center for Cancer Research, National Cancer Institute, National Institutes of Health, Bethesda, MA, USA and ${ }^{2}$ Molecular and Cellular Biology, Baylor College of Medicine, Houston, TX, USA

Correspondence: Dr RI Linnoila, MD, Experimental Pathology Section, Cell and Cancer Biology Branch, CCR, NCl, NIH, 37, Convent Drive; Bg. 37 Room no.1056B, Bethesda, MD 20892, USA. E-mail: linnoila@mail.nih.gov 
$10 \mathrm{kDa}$ protein (CC10) promoter which directs gene expression to Clara cells. ${ }^{12,13}$ They are nonciliated secretory cells that are most abundant in distal airways. They are also progenitors for the normal and neoplastic peripheral airway epithelium, which makes them a highly relevant target. ${ }^{14,15}$ The CC10-hASH1 mouse yields a characteristic phenotype featuring remodeling of airway epithelium at the bronchioloalveolar duct junction (BADJ) resulting in bronchiolization of alveoli (BOA). ${ }^{16,17}$ This is significant as BADJ harbors one of the lung stem cell niches and is the critical border of two biologically and developmentally different parts of the distal lung, the bronchiolar and alveolar compartments. ${ }^{18,19}$ On the other hand, BOA is a histologically distinct entity, which is a feature of many pathological conditions including fibrosis and chronic inflammation. ${ }^{20}$ Notably, BOA lesions are also found in lung cancer resection specimens suggesting they may be part of field cancerization and represent a novel premalignant lesion especially for peripheral carcinomas whose incidence is increasing. ${ }^{21}$ Yet, the paucity of suitable human samples has long hampered the studies of mechanism of progenitor lesions in the lung.

It is not clear how and why constitutive hASH1 expression leads to BOA. In the present study, we analyzed proliferation and apoptosis in terminal bronchioles (TBs) and BOA during remodeling. Our results suggest that hASH1 promotes resistance to apoptosis. We then focused on identifying candidate pathways that may include $\mathrm{Bcl}-2$, Akt, $\mathrm{c}-\mathrm{Myb}$, matrix metalloproteinase 7 (MMP7) and CC10. Knockdown and overexpression of hASH1 in well-characterized human lung cell lines provided a functional link in vitro. We conclude that constitutive expression of hASH1 in lung epithelial progenitor cells promotes remodeling via many of the same genes that are important for lung carcinogenesis. This is consistent with the notion that $\mathrm{BOA}$ is a premalignant lesion.

\section{MATERIALS AND METHODS Human and Mouse Tissues}

Human BOA lesions were identified as described previously. ${ }^{21}$ Routine formalin-fixed paraffin-embedded material from seven surgical lung resection specimens was used. All patients belonged to approved clinical protocols. CC10-hASH1 transgenic mice were generated as described previously. ${ }^{17}$ Transgenic incorporation was verified using tail DNA Southern analysis as well as PCR; 29 transgenic and 21 wild-type (WT) litter mates were examined at the age 1-12 months. Lungs were removed from mice and divided as follows: one lobe was fixed in $4 \%$ neutral-buffered paraformaldehyde overnight and embedded in paraffin for morphometry and immunohistochemistry (IHC) and another one embedded in optimal cutting temperature gel for laser capture microdissection (LCM). The rest of the lung was snap-frozen for protein and RNA analyses. Samples were stored at $-80^{\circ} \mathrm{C}$ until use.

\section{Morphometry, IHC and Apoptosis In Situ}

For morphometric and quantitative analyses mouse airway epithelium was divided into three categories according to following criteria: (1) bronchioli (BL) composed of intrapulmonary airways in which smooth muscle, but neither cartilage nor glands could be seen, (2) TBs with an intact BADJ (Figure 1) and a visible alveolar $\operatorname{duct}^{18}$ and (3) BOA as cells resembling bronchiolar epithelium lining normal or thickened alveolar walls (Figure 1), often in an acinar formation, as described by Nettesheim and Szakal. ${ }^{20}$ The length of epithelium and the area of BOA were analyzed using Nikon Eclipse $600^{\circledR}$ microscope and MetaMorph ${ }^{\circledR}$ software (Molecular Devices Corporation, Downingtown, PA, USA; Figure 1).

IHC was performed on paraffin-embedded tissue using avidin-biotinylated peroxidase method and Vectastain $A B C$ kits (Vector, Burlingame, CA, USA). The primary antibodies (Supplementary Table S1) were incubated for overnight at $4^{\circ} \mathrm{C}$ and signals were visualized using $3,3^{\prime}$-diaminobenzidine tetrahydrochloride as described previously. ${ }^{22}$ Tissue sections were counterstained with Mayer's hematoxylin or light green.

Proliferation in vivo was determined by proliferating cell nuclear antigen (PCNA) immunostaining or $5^{\prime}$-bromo2'-deoxyuridine (BrdU) incorporation. Two hours before killing, mice were given intraperitoneally $70 \mathrm{mg} / \mathrm{kg}$ of body weight BrdU (Sigma, St Louis, MO, USA). Visualization was performed on deparaffinized lung tissue sections as described previously using a rat monoclonal antibody against BrdU (Harlan Sera Laboratories Ltd., Loughbrough, UK). ${ }^{23,24}$

Apoptosis in situ was detected by terminal deoxynucleotidyl transferase (TdT)-mediated dUTP nick end labeling (TUNEL) using ApopTag Peroxidase Kit (Serologicals

Figure 1 Characterization of the CC10-hASH1 transgenic model. (a) Photomicrograph of a normal BADJ in a WT mouse. Note the sharp demarcation of the airway and alveolar type epithelia (arrows, hematoxylin and eosin staining; bar =50 $\mu \mathrm{m}$ ). (b) Photomicrograph of BOA (lined by red, arrows) in a 4-monthold CC10-hASH1 transgenic mouse. Note hyperplastic airway epithelium in the TB. In this study, TB was defined as a small bronchiolus with visible BADJ. In panel e, $200 \mu \mathrm{m}$ of the most distal TB epithelium adjacent to BADJ (indicated by a black line) was used for morphometric analysis (hematoxylin and eosin staining; bar $=50 \mu \mathrm{m}$ ). (c) An increase in number of cells (mean \pm s.e.m.) in BOA lesions at 4 and 12 months compared to 1 month. (d) Increased area of BOA (mean \pm s.e.m.) per TB at 4 and 12 months compared to 1 month. (e) An increase in number of cells per $100 \mu \mathrm{m}$ in the most distal parts of transgenic animals compared to WT. H, CC10-hASH1 transgenic mouse, m, month. Statistical analysis: ${ }^{\star} P<0.05,{ }^{\#} P<0.01,{ }^{*} P<0.001$. (f) Frozen section of two BOAs (1, 2 indicated by arrows) before LCM (hematoxylin staining). (g) Same section following LCM, as most of the cells in BOAs (1, 2 arrows) have been removed. (h) Dissected tissue on the cap used for RNA extraction (1, 2). (i) Immunoreactivity of endogenous ASH1 is limited to a small group of NE cells (arrow) in the airway epithelium of WT mouse (immunoperoxidase staining). (j) In transgenic mice, nuclear expression of ASH1 is seen throughout the airway epithelium and BOA lesions (arrows, immunoperoxidase staining). (k) Quantitative RT-PCR analysis of microdissected (LCM) tissues revealed expression of hASH1 throughout the epithelium and BOA in transgenic mice. A bar represents a mean \pm s.e.m. of material from three mice at the age of 4 months. No expression was seen in WT animals. 

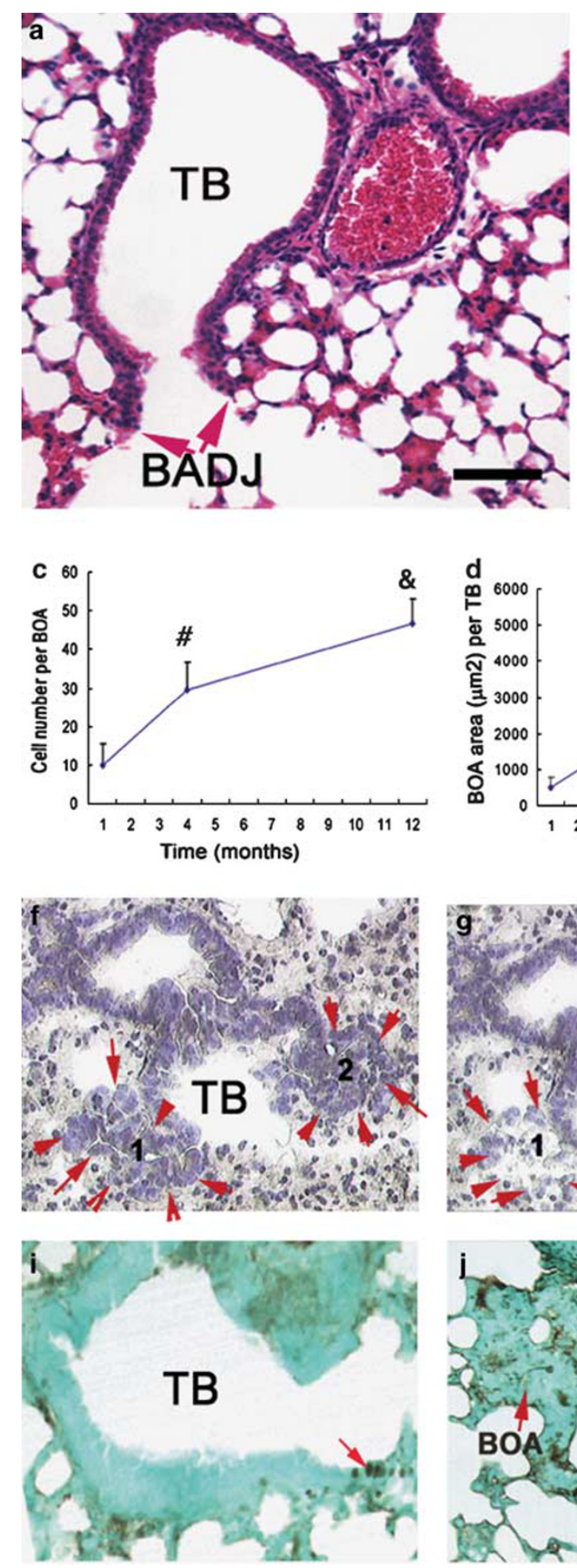
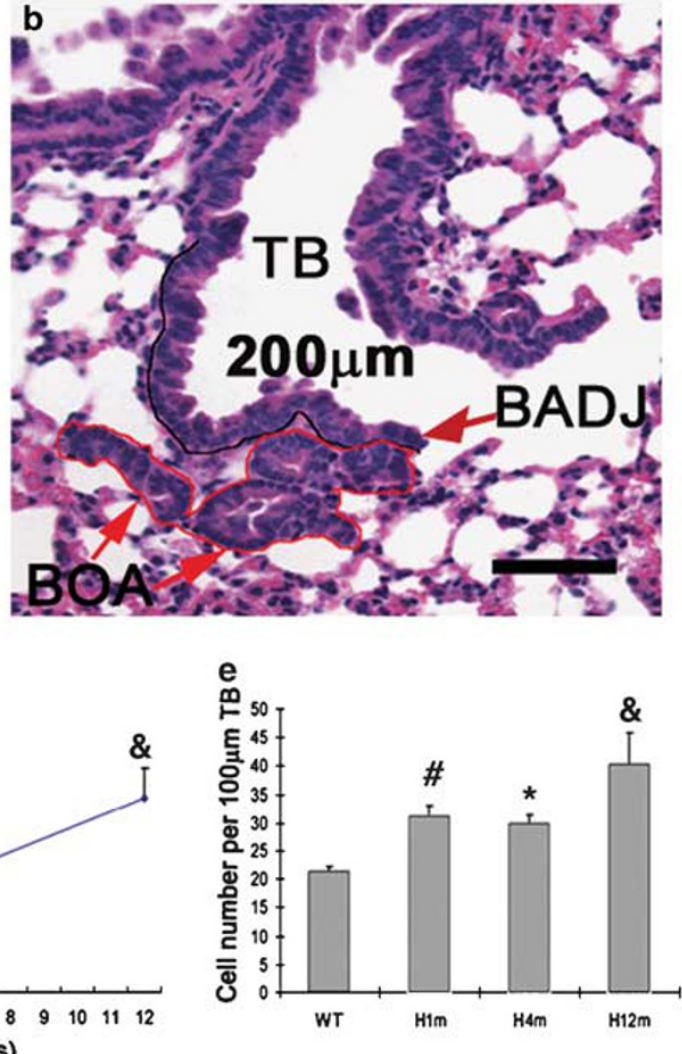

h
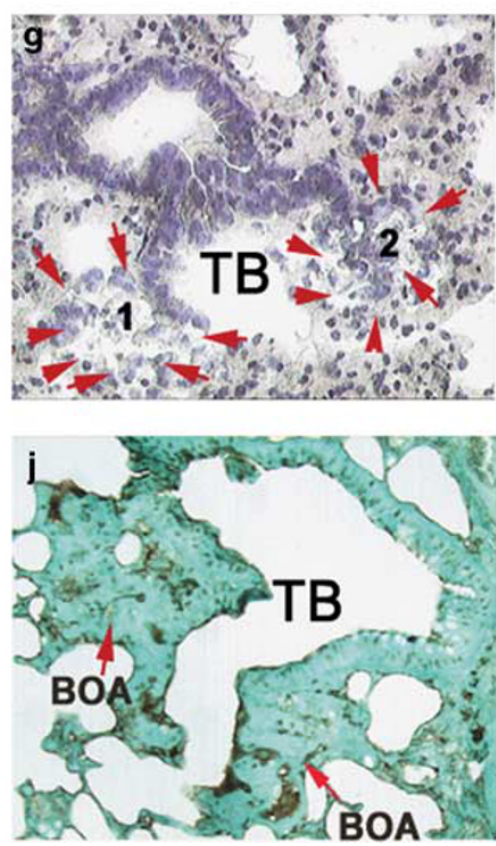

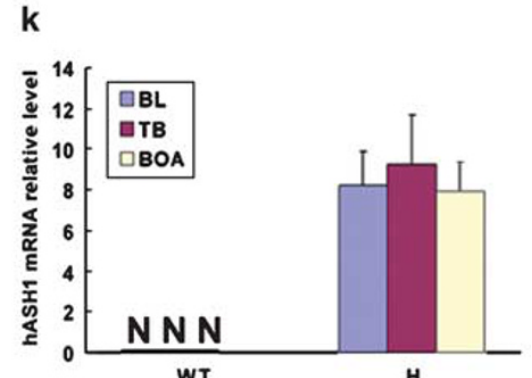

WT
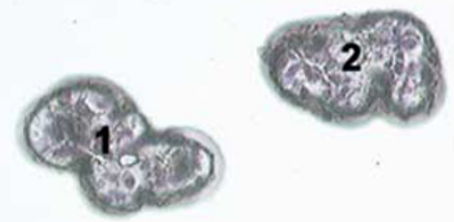

Corporation, Milford, MA, USA) following the manufacturer's instructions.

Labeling indices (percent of labeled cells) were established by counting positive and negative cells in BL, TBs and BOAs. Typically, we counted a total of 600-1500 cells for a marker per mouse in each category of epithelium including BOA
(Figure 2), cells located $200 \mu \mathrm{m}$ from BADJ in 3 to 4 TBs and $1500-2000 \mu \mathrm{m}$ of epithelium in BLs in a lung section.

\section{Laser Capture Microdissection}

LCM was performed as described previously with few modifications. $^{16,25}$ LCM from $7 \mu \mathrm{m}$ thick frozen sections 

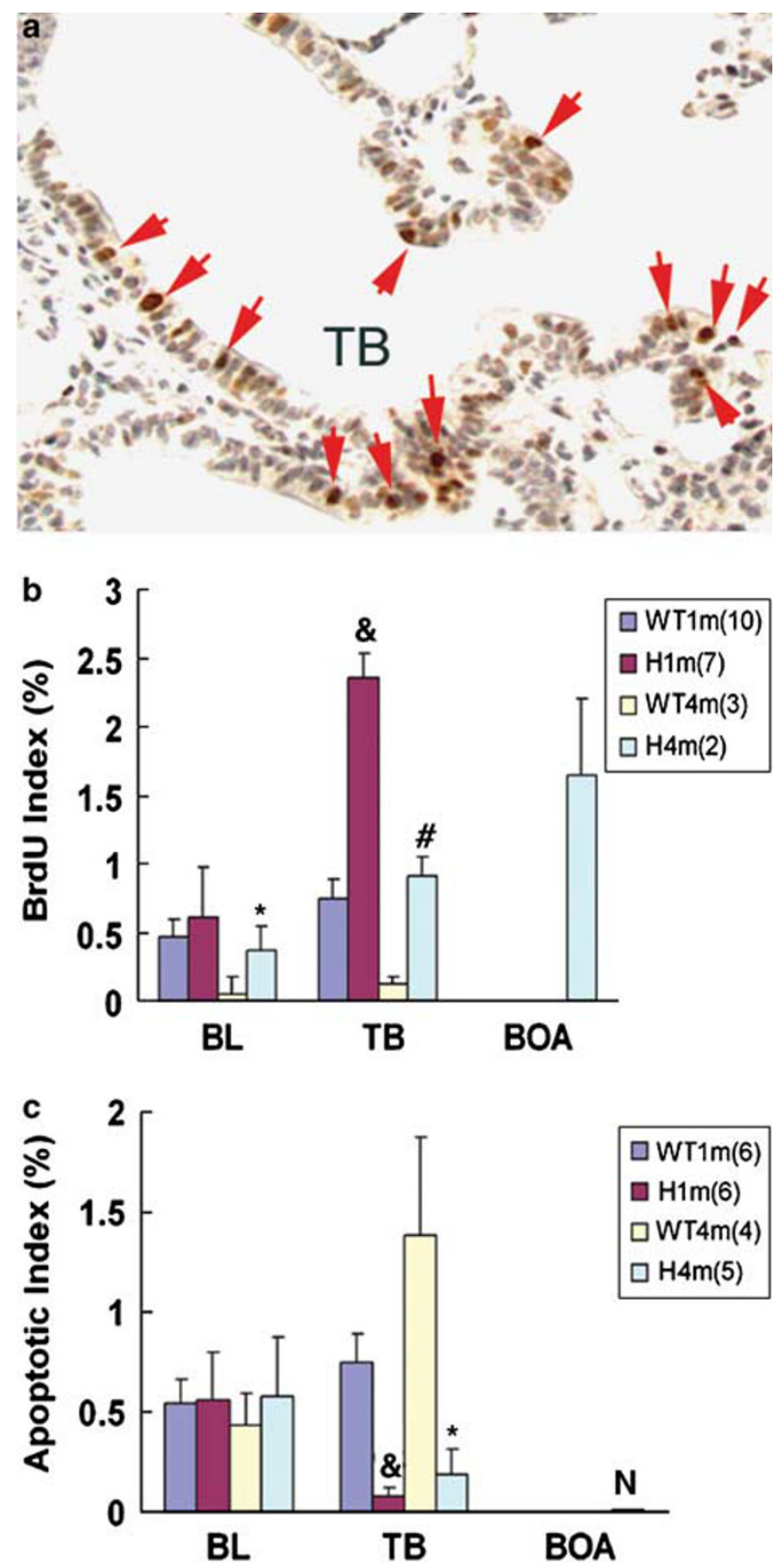

Figure 2 Increased proliferation and decreased apoptosis in CC10-hASH1 mice contribute to remodeling in BADJ. (a) PCNA immunostaining of transgenic mouse TB epithelium revealed multiple positive nuclei (arrows). (b) Quantitation of BrdU labeling indexes (mean percent of positive cells \pm s.e.m.) by the type of epithelium and age in WT and transgenic mice. Highest levels were noted in TBs of 1-month-old transgenic mice, followed by BOA at 4 months. (c) A bargraph of apoptotic index (mean percent of positive cells \pm s.e.m.), which was significantly lower in TBs of CC10-hASH1 mice than in TBs of WT mice. The index remained unchanged in BL. $H$, CC10-hASH1 transgenic mouse; $\mathrm{m}$, month; $N=0$ (no labeling). The number of mice is given in parentheses. Statistical comparisons $(\mathbf{b}, \mathbf{c})$ between WT and transgenic mice in each age group and category of epithelium (BL, TB and $\mathrm{BOA}$ ): ${ }^{*} P<0.05,{ }^{\#} P<0.01,{ }^{\&} P<0.001$.

was performed using an Arcturus PixCell II LCM system (Arcturus Engineering, Mountain View, CA, USA) with the following parameters: laser diameter, $15 \mu \mathrm{m}$; pulse duration, $1.5 \mathrm{~ms}$; and amplitudes $30-40 \mathrm{~mW}$. TB epithelium was retrie- ved from the BADJ (Figure 1) proximally along the bronchiole $\sim 200 \mu \mathrm{m}$. A total of $10000-20000$ bursts of the laser were used to collect cells from each mouse. After microdissection, non-specific attached components were removed by adhesive tape (CapSure Pad; Arcturus Engineering) and tissue that had adhered to the CapSure ${ }^{\mathrm{TM}}$ Macro LCM caps film (Arcturus Engineering) was pooled and eluted in $300 \mu \mathrm{l}$ RLT lysis buffer containing $1 \%$ $\beta$-Mercaptoethanol included in the RNeasy Micro Kit (Qiagen) using $0.5 \mathrm{ml}$ autoclaved thin-walled reaction tubes (Perkin Elmer, Norwalk, Connecticut). The LCM sample for real-time reverse transcription-polymerase chain reaction (RT-PCR) was stored at $-80^{\circ} \mathrm{C}$ until used.

LCM for Western blot (WB) analysis was based on the methods described by Jones et al. ${ }^{26}$ LCM samples of three mice at the age of 4 months for each category (BL, TB and BOA) were pooled (Figure 3i). Estimated cells in $30 \mu \mathrm{l}$ were 30000 cells. Samples were stored at $-20^{\circ} \mathrm{C}$ until use.

\section{Cell Lines}

DMS53, a SCLC line, ${ }^{27}$ was a gift from Dr Douglas Ball (Johns Hopkins University, Baltimore, MD, USA), NCI-H727 was a gift from Dr Adi Gazdar (University of Texas Southwestern Medical Center, Dallas, TX, USA). NCI-H23 and BEAS-2B were purchased from the American Type Culture Collection (Manassas, VA, USA). DMS53 cell line was grown in Waymouth's medium (Life Technologies, Rockville, MD, USA) supplemented with $16 \%$ fetal bovine serum (FBS), 100 units of penicillin and $100 \mu \mathrm{g}$ of streptomycin per ml. NCIH23 and NCI-H727 cell lines were grown in RPMI 1640 (Life Technologies) supplemented with 10\% FBS, 100 units of penicillin and $100 \mu \mathrm{g}$ of streptomycin per $\mathrm{ml}$ at $37^{\circ} \mathrm{C}$ and $5 \%$ $\mathrm{CO}_{2}$. The BEAS-2B cells were, upon arrival, flash thawed and cultured in bronchial epithelial cell growth medium with 'bullet kit' additives (Cambrex Bio-science, Walkersville, MD, USA) composed of growth factors and antibiotics.

\section{Cell Proliferation and Apoptosis Assay In Vitro}

Cell proliferation assay based on the ability of live cells to utilize thiazolyl blue and convert it into dark blue formazan was used (MTT kit V-13154; Invitrogen). In brief, 10000 cells/well (in 96-well microtiter plates) in $0.2 \mathrm{ml}$ of culture medium were seeded. At every 24 or $48 \mathrm{~h}$ (for siRNA) $10 \mu \mathrm{l}$ of $12 \mathrm{mM}$ MTT were added to each well and incubated with cells at $37^{\circ} \mathrm{C}$ for $4 \mathrm{~h}$. Then $0.1 \mathrm{ml}$ of $10 \mathrm{mM} \mathrm{HCl}$ containing 1 gram of SDS was added to each well at room temperature for overnight. The absorbance at a wavelength of $562 \mathrm{~nm}$ was measured with a micro-ELISA reader (Bio-Rad, Hercules, CA, USA). Each assay was performed in triplicate.

Flow cytometric analysis of apoptosis was performed as described elsewhere. ${ }^{28}$ Adherent cells were harvested by trypsinization and centrifuged at $1000 \mathrm{~g}$ for $5 \mathrm{~min}$. Cells were fixed in ice-cold $70 \%$ ethanol added dropwise and incubated at $-20^{\circ} \mathrm{C}$ for $30 \mathrm{~min}$. Cells were centrifuged and incubated with propidium iodide $(25 \mu \mathrm{g} / \mathrm{ml})$ supplemented with 

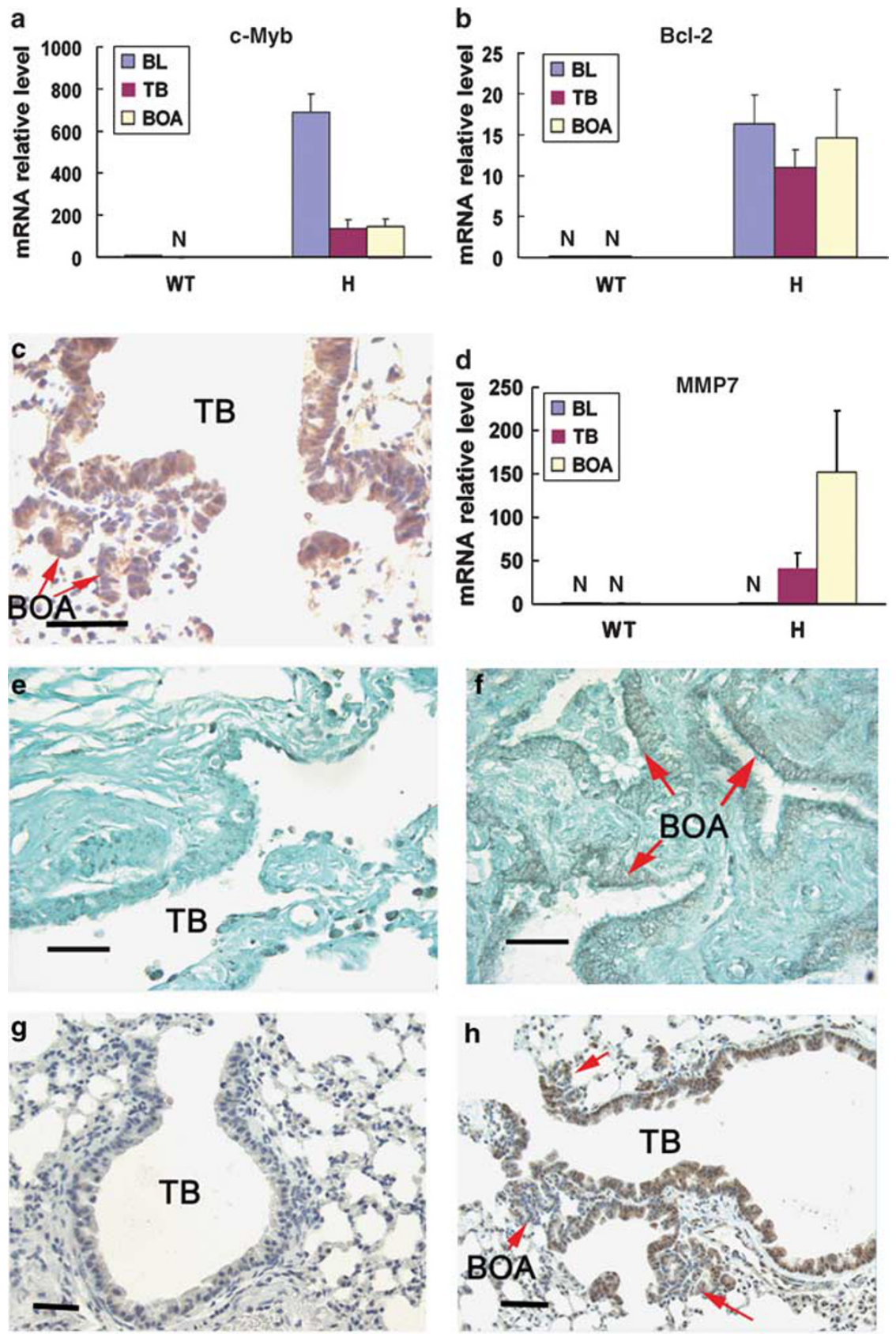

i

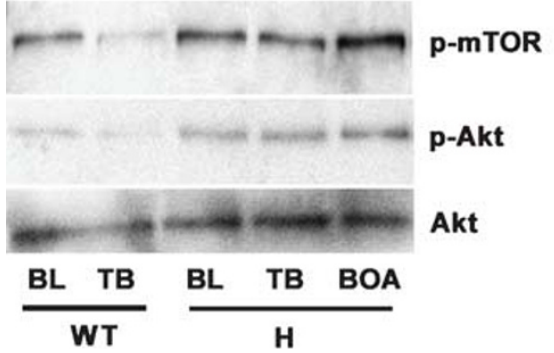

Figure 3 Effectors of cellular dynamics during remodeling in CC10-hASH1 transgenic mouse and human lung. (a) The level of c-Myb mRNA in BL, TB and $\mathrm{BOA}$ in CC10-hASH1 mice was higher than that in WT mice. Highest levels of c-Myb mRNA were seen in $\mathrm{BL}$ of transgenic mice. (b) The expression level of $\mathrm{Bcl}-2$ mRNA was comparable in $\mathrm{BL}, \mathrm{TB}$ and $\mathrm{BOA}$ in transgenic mice, while no expression was seen in WT mice. (c) Moderate immunoreactivity for MMP-7 was seen in TBs and BOA lesions of transgenic mice. (d) Highest mRNA levels of MMP7 were detected in BOA lesions of CC10-hASH1 mice. In panels $a, b$ and $d$, bars represent a mean \pm s.e.m. relative level of mRNA from three mice; qRT-PCR measurement of LCM specimens. $N=0$ (no expression). (e) Photomicrographs of human normal TB negative for MMP7 and (f) human BOA positive for MMP7 (immunoperoxidase). (g) Photomicrographs of minimal expression of p-Akt in WT epithelium, and (h) moderate immunoreactivity in $\mathrm{TB}$ and $\mathrm{BOA}$ of a transgenic mouse. (i) WB of LCM specimens reveals increased levels of p-mTOR and p-Akt S473 in CC10-hASH1 mice. (j) Quantitation (Scion ${ }^{\mathbb{R}}$ software) of relative $p$-Akt protein levels in the various epithelia. The data presented in panels $a-d$ and $g-j$ were derived from mice that were 4 months old. Bar $=50 \mu \mathrm{m}$ (c and $\mathbf{e}-\mathbf{h})$.
RNaseA (BD Pharmingen ${ }^{\text {TM }}$ San Diego, CA, USA) for $30 \mathrm{~min}$ at room temperature. Quantification of sub-G1 DNA was determined by flow cytometric analysis using a BD
Pharmingen $^{\mathrm{TM}}$ FACSort and by manual gating using CellQuest software. Gating was performed on blinded samples. Experiments were repeated three times. 


\section{Cell Invasion and Migration In Vitro}

For invasion assay $1 \times 10^{5}$ cells/well of BEAS-2B and $0.5 \times 10^{5}$ cells/well of NCI-H23 were plated onto 24-well Matrigel coated inserts ( $8 \mu \mathrm{m}$ pore size) (BD Biosiences Discovery Labware, Bedford, MA, USA) and incubated at $37^{\circ} \mathrm{C}, 5 \% \mathrm{CO}_{2}$ atmosphere for $24-40 \mathrm{~h}$. Chemoattractants which were added into the bottom of the wells included 10\% FBS and $20 \mathrm{ng} / \mathrm{ml}$ IGF for BEAS-2B and 5\% FBS for NCI-H23. After incubation noninvading cells were removed from the top of the wells with a cotton swab, followed by fixation and staining with $0.25 \%$ crystal violet in $25 \%$ ethanol. All experiments were completed in triplicate and the cells on each insert well were counted. For migration assay all procedures were same as invasion assay except for uncoated chambers ( $8 \mu \mathrm{m}$ pore size; BD Biosiences Discovery Labware, Bedford, MA, USA).

\section{Small RNA Interference and Transfection of hASH1}

Three siRNAs for targeting hASH1 (National Center for Biotechnology Information (NCBI) accession number: NM004316) were designed and synthesized by Ambion Inc. (Austin, TX, USA; Supplementary Table S2). DMS53 and NCI-H727 cell lines were transfected with siRNAs using $\mathrm{RNAiFect}^{\mathrm{TM}}$ transfection reagent kit protocol (Qiagen) with $200 \mathrm{nM}$ of siRNA for $72 \mathrm{~h}$ (Figure 4).

For the transfection, hASH1 gene was inserted into pcDNA 3.1/V5-His ${ }^{\circledR}$-TOPO ${ }^{\circledR}$ TA plasmid and transfected into TOP10 Escherichia coli cells using the Invitrogen Expression Kit. After selection and analysis of the TOP10 E. coli cells, purified plasmid was prepared for transfection. Two micrograms of plasmid DNA were transfected into BEAS-2B and H23 using Lipofectamine-Plus Reagent kit (Invitrogen) in $100 \mathrm{~mm}$ dish. Following G418 treatment, cells derived from a single colony were cultured at least 4 weeks with a selective antibiotic for hASH1 stable expression. The expression of the gene was tested by Western blot or immunostaining and RTPCR (Figure 5).

\section{RNA Isolation, Reverse Transcription and Quantitative Real-Time PCR}

Total RNA was extracted from LCM samples using RNeasy Micro Kit (Qiagen) and from cultured cells using RNeasy Mini-kit followed the manufacturer's protocol. Genomic DNA was digested by incubation with RNase-free DNase set for $15 \mathrm{~min}$ at room temperature.

Five microlitres of RNA extract from LCM samples, containing an unknown amount of RNA, was reverse-transcripted using random hexamers (Invitrogen) and Sensiscript RT kit (Qiagen). One microgram of RNA from cultured cells was reverse transcribed in a total volume $20 \mu \mathrm{l}$ using Omniscript RT kit (Qiagen). Quantitative PCR was carried out using an iCycler iQ ${ }^{\mathrm{TM}}$ Multi-Color real time PCR detection system (BioRad, Hercules, CA, USA). Specific amplification using the primers was confirmed by ethidium bromide staining of the PCR products on an agarose gel. The probes were labeled with 6-carboxyfluorescein (FAM) at the $5^{\prime}$ end and 6-carboxy- tetramethyl-rhodamine (TAMRA) at the $3^{\prime}$ end. Primers and labeled probes (Supplementary Table S3) were purchased from Synthegen LLC (Houston, TX, USA). PCR was carried out in duplicate using a QuantiTect ${ }^{\mathrm{TM}}$ probe PCR kit (Qiagen) according to the manufacturer's protocol. The PCR for the target gene and GAPDH or $\beta$-actin were performed in separate tubes to avoid possible competition and/or interference in a single reaction tube..$^{29,30}$

\section{Western Blotting}

WB analysis was performed using the Criterion ${ }^{\mathrm{TM}}$ system (Bio-Rad). Cells were lysed on ice in lysis buffer. Protein yield was quantified using the BCA protein assay reagent kit (Pierce, Rockford, IL, USA). Twenty micrograms of protein or $30 \mu \mathrm{l} \mathrm{LCM} \mathrm{lysis} \mathrm{sample} \mathrm{was} \mathrm{loaded,} \mathrm{and} \mathrm{the} \mathrm{lysates} \mathrm{were}$ separated by SDS-PAGE (Bio-Rad) and transferred to PVDF membranes (Amersham Biosciences, Piscataway, NJ, USA). Primary antibodies (Supplementary Table S1) were detected using horseradish peroxidase-linked goat antibodies and visualized with chemiluminescence (Amersham Biosciences).

\section{Statistics}

One-way ANOVA analysis was used for data. The data were transcribed into SPSS software, version 10 (SPSS Inc., Chicago, IL, USA).

\section{RESULTS}

\section{Phenotype of Remodeling and BOA}

To elucidate the cellular changes in transgenic mouse lungs, we performed a detailed evaluation of the hematoxylin-eosinstained histologic sections. Morphometric analyses of the CC10-hASH1 mouse lungs revealed almost a fivefold increase in cell number and eightfold increase in the area of BOAs over 12 months (Figures 1a-d). The impact of hASH1 expression was also seen in TBs, whose cellularity doubled (Figure 1e) in transgenic mice when compared with wild type mice (40 vs 21 cells per $100 \mu \mathrm{m}$ of basement membrane, respectively). It should be noted that throughout the study, we focused on the most distal $200 \mu \mathrm{m}$ of TB epithelium (Figure 1b), which has the highest density of Clara cells and most closely resembled BOA. In WT mice there was no change in the cellularity of TBs over time. In summary, the transgenic mice revealed increased cellularity in TBs and continuous expansion of BOAs.

\section{Expression of the Transgene, Calcitonin Gene-Related Peptide and Endogenous CC10}

To verify hASH1 and CC10 expression in the airways, we used both IHC and quantitative real-time reverse transcriptase (qRT-PCR) following LCM enrichment (Figures 1f-k). Three categories of epithelium were included: BL, TBs and BOAs. In WT mice endogenous mASH1 and CGRP protein expression was limited to occasional solitary PNECs and clusters called neuroepithelial bodies. In CC10-hASH1 mice hASH1 immunoreactivity was detected in nuclei 
a

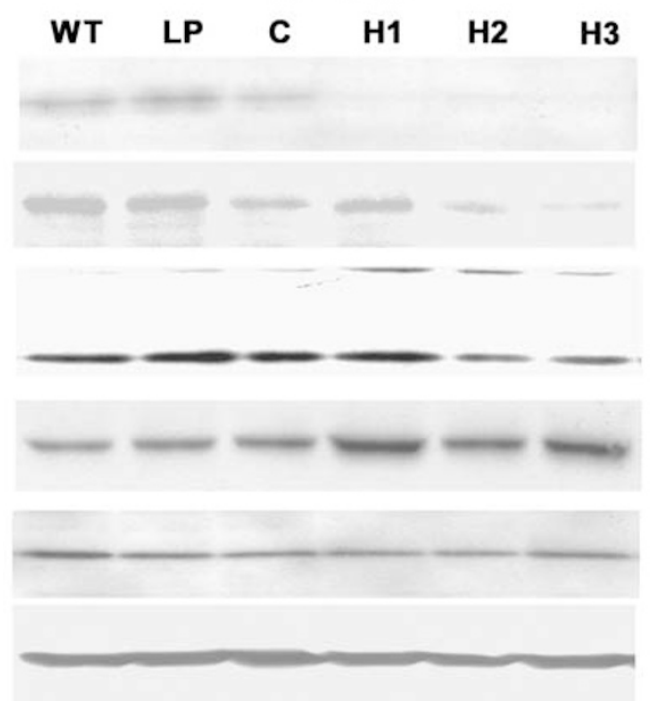

b
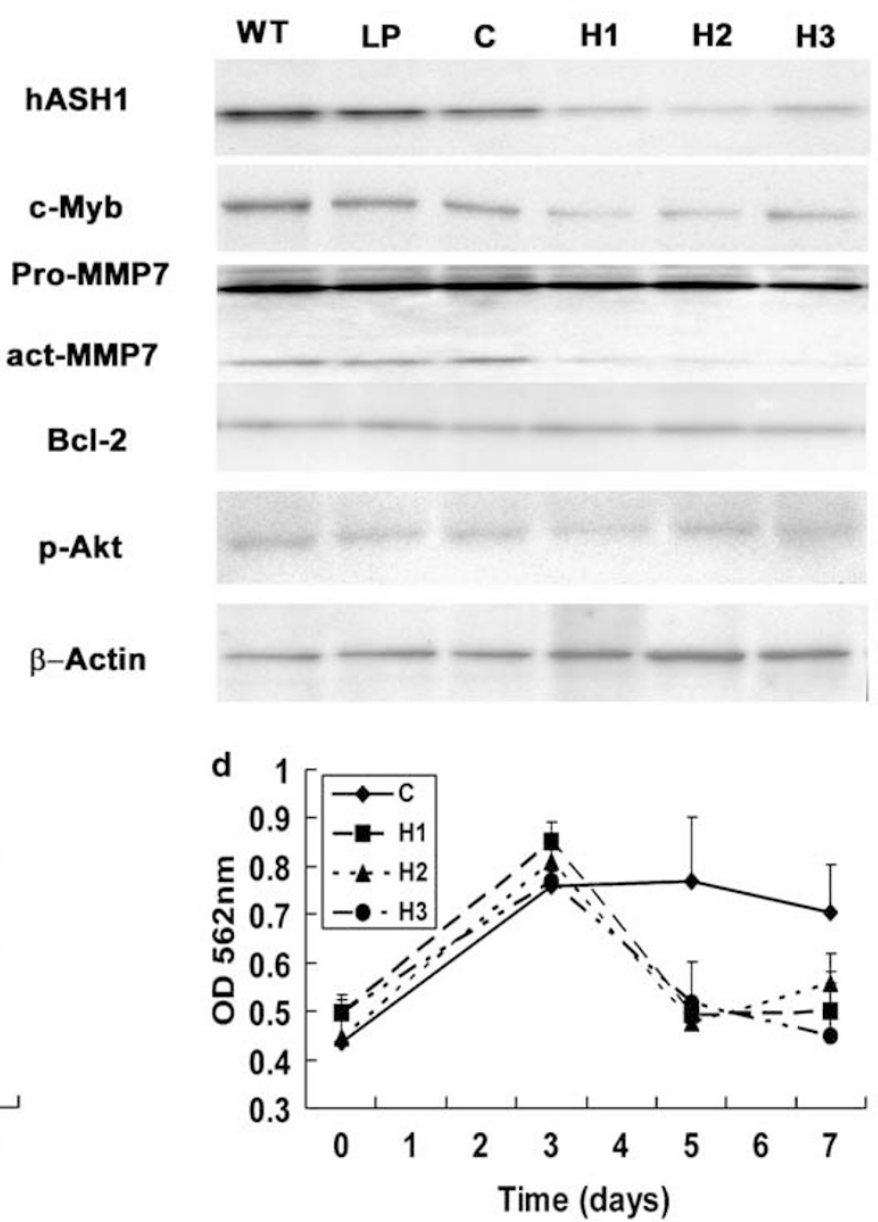
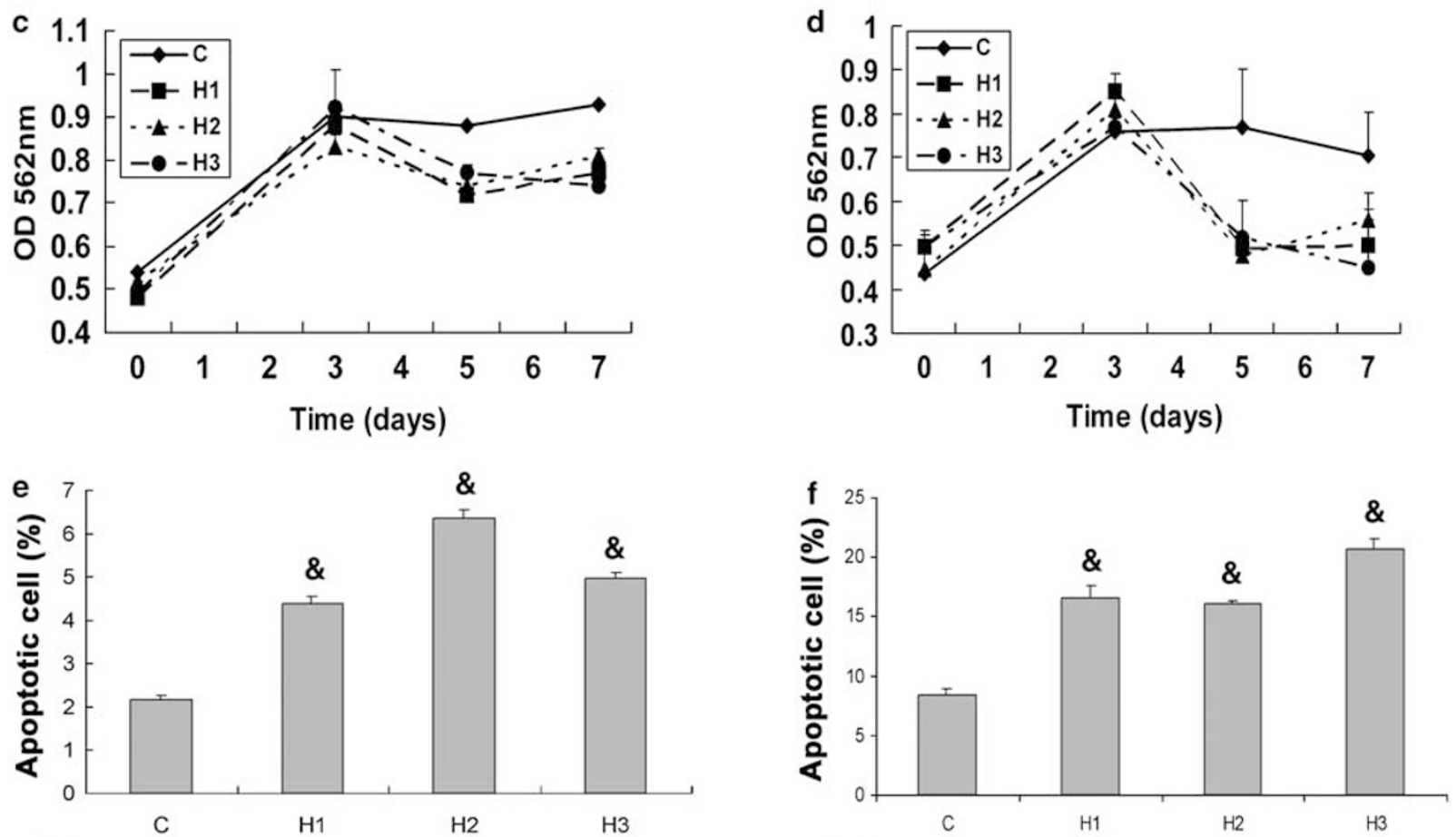

WB
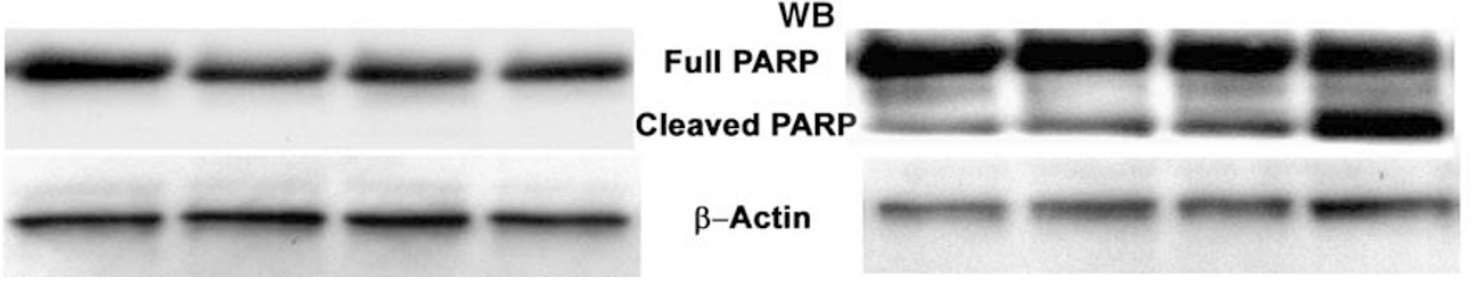

Figure 4 Impact of hASH1 knockdown in human lung NE cancer cell lines. Cell lines were transfected with $200 \mathrm{nM}$ of three different hASH1 siRNA sequences ( $\mathrm{H} 1, \mathrm{H} 2$ and $\mathrm{H} 3$ ) and a non-silencing RNA sequence as a control for $72 \mathrm{~h}$. WB of (a) NCl-H727 pulmonary carcinoid and (b) DMS53 SCLC cell line. WT, wild type (no treatment); LP, lipofectamine; C, control RNA. All three siRNAs (H1-3) resulted in downregulation of hASH1 expression. (c) and (d) MTT assay showed decreased cellular proliferation at days 5 and 7 following siRNA treatment (mean \pm s.e.m.). (e) and (f) The percent of apoptotic cells (sub-G1 population) in both cell lines was increased at $72 \mathrm{~h}$ (mean \pm s.e.m.; FACS analysis) compared with control ( $\left.{ }^{\&} P<0.001\right)$. Increased apoptosis induced by siRNA was confirmed by increased cleaved poly(ADP-ribose) polymerase (PARP) using WB in DMS53 cell line (f, bottom panel); no product was detected in H727 (e, bottom panel). 
a

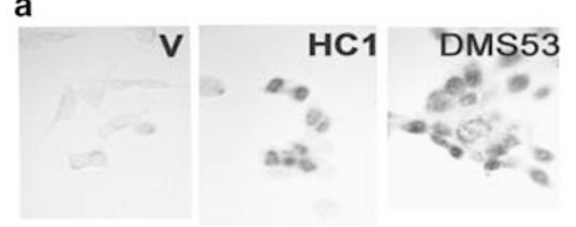

c

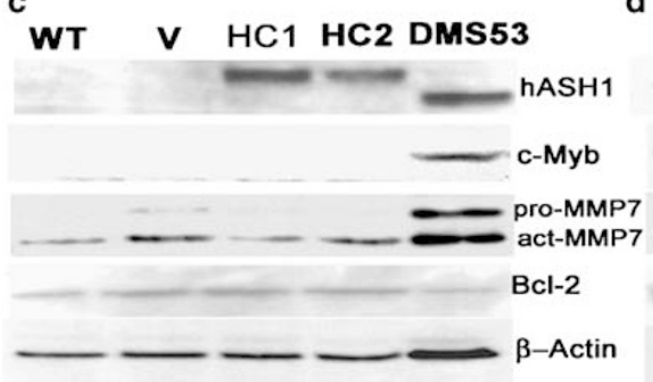

b

\section{WT V HC1 HC2 DMS53}

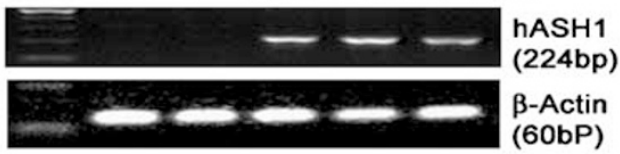

d

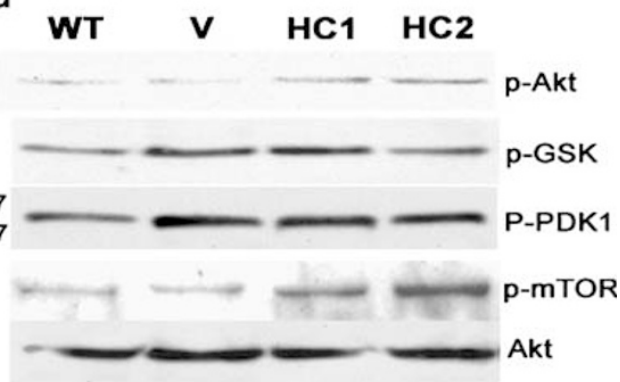

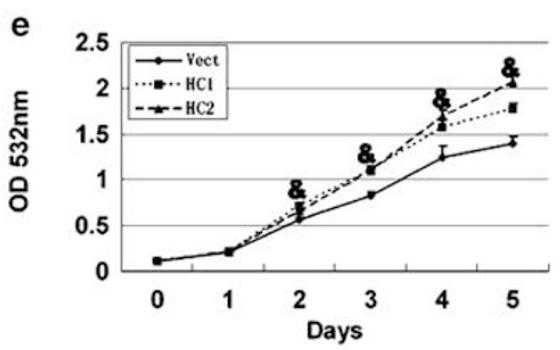

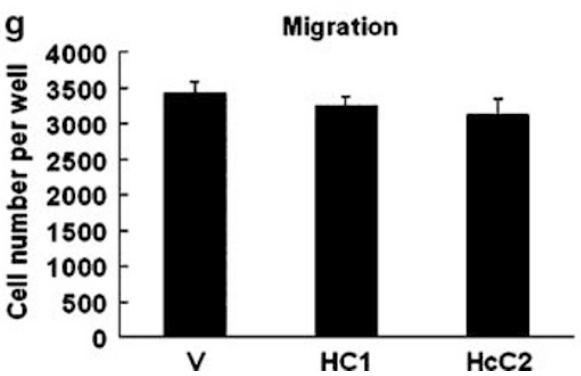

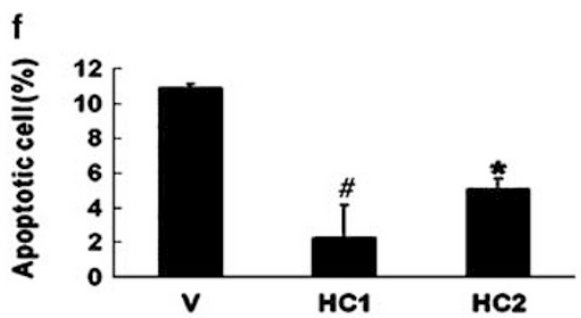

h

Invasion

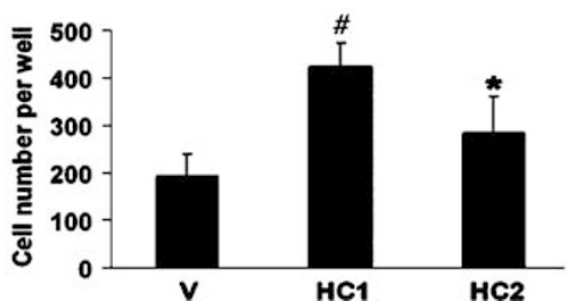

Figure 5 Forced expression of hASH1 promoted cell growth and decreased apoptosis in immortalized normal human bronchial epithelial cells (BEAS-2B). (a) Photomicrographs of hASH1 immunoreactivity. Strong nuclear immunoreactivity in clone HC1 comparable to positive control (DMS53) cells. (b) RT-PCR confirms the expression of hASH1 mRNA in clone HC1 and 2. (c) and (d) WB analysis of transfected BEAS-2B cells. The endogenous hASH1 in DMS53 cells migrates faster ( $34 \mathrm{kDa}$ ) than the epitope-tagged hASH1 (38 kDa) in transfected clones HC1 and 2, while WT and V controls are negative. (e) MTT assay revealed increased growth following hASH1 transfection (from day $2,{ }^{\&} P<0.001$, compared with vector control, $n=12$ ). (f) Percent of apoptotic cells (sub-G1 population) was significantly decreased using FACS analysis at $72 \mathrm{~h}$. (g) Cell migration assay. (h) Cell invasion was increased in both hASH1-positive clones. Data, mean \pm s.e.m., compared with cells $V,{ }^{*} P<0.05,{ }^{\#} P<0.01$. M, molecular markers; WT, wild type (parental cell line); $V$, transfected with empty vector; HC1-2, hASH1-transfected clones 1 and 2.

throughout the airway epithelium consistent with its transcriptional role. Accordingly, qRT-PCR revealed uniform expression of hASH1 mRNA in all airway and BOA samples of the transgenic animals, while there was no expression in WT mice.

The expression of the NE marker CGRP was further evaluated in the lung tissues from WT (a total of 103 TBs) and transgenic (a total of 209 TBs and BOAs) mice by IHC. Only two out of $21 \mathrm{WT}$ and two out of 29 transgenic mice demonstrated CGRP immunoreactive cells in TBs. No CGRPcontaining cells were found in BOAs of transgenic mice
(Supplementary Figure S1). This result indicates extreme sparsity or lack of NE differentiation in the BADJ and BOAs of CC10-hASH1 mice. CC10 immunoreactivity was reduced in TBs and BOAs of transgenic mice, which correlated with the mRNA levels (data not shown). In other words, the transgene was expressed throughout the airway epithelium and BOAs, while endogenous CC10 levels were reduced.

\section{hASH1 Confers Resistance to Apoptosis}

Airway epithelium is a conditionally renewing tissue with a very slow proliferation rate in a normal state. ${ }^{31}$ As any 
growth is a balance between cell proliferation and death, we analyzed PCNA immunostaining and BrdU incorporation for proliferation and TUNEL (Figure 2) for apoptosis. As illustrated in Figure 2a, PCNA immunostaining level was high in transgenic mice (data not shown). There was also a dramatic increase in BrdU incorporation in TBs at one month of age. By 4 months, the labeling index was sevenfold in BL and TBs when compared to the levels in WT mice (Figure 2b). The levels in BOA lesions were also elevated. Apoptotic index was markedly reduced in TBs of transgenic mice and, strikingly, no TUNEL-positive cells were detected in BOAs (Figure 2c). The data suggest that the most dramatic response to hASH1 includes early and sustained cellular proliferation in TBs and lack of apoptosis in BOAs.

\section{Patterns of Bcl-2, c-Myb, MMP7 Expression and Activation of Akt Pathway}

To elucidate the potential mechanism for the cellular proliferation and resistance to apoptosis in the CC10-hASH1 mouse lung, we determined the spatial expression of several genes known to contribute to human lung carcinogenesis (Figure 3) using LCM and IHC.

One of the potential downstream effectors of ASH1 in a mouse prostate cancer model is $\mathrm{c}-\mathrm{Myb} .{ }^{32}$ The proto-oncogene $\mathrm{c}-\mathrm{Myb}$ codes for nuclear proteins involved in transcriptional regulation and appears to be essential for cell proliferation. ${ }^{33}$
Our analysis demonstrated markedly elevated c-Myb mRNA expression in BL and lower levels in TBs and BOAs. In contrast, the expression of $\mathrm{c}-\mathrm{Myb}$ in WT mice was very low in BL and negative in TBs (Figure 3a). This was confirmed by IHC.

$\mathrm{Bcl}-2$ is one of the anti-apoptotic genes frequently expressed in lung cancer. Moderate to strong immunoreactivity was found in all airways of transgenic mice while WT epithelium was negative. Moreover, mRNA was also expressed throughout the airways and BOAs of CC10-hASH1 mice (Figure 3b). While we observed some survivin expression by IHC we were unable to confirm this by RT-PCR (data not shown).

We also tested a number of MMPs and TIMPs that potentially modulate the migration, invasion and growth of airway cells ${ }^{34,35}$ (Table 1). mRNA levels of MMP2, MMP7, MMP9 were selectively increased in TBs and BOA lesions in transgenic mice, compared to TBs of WT mice, while the mRNA levels of MMP13 and TIMP1 were dramatically decreased. TIMP2 expression was also decreased in TBs and BOAs, albeit the difference was not statistically significant. Interestingly, we failed to detect any MMP7 mRNA in BL and TBs of WT mice and in BL of CC10-hASH1 mice, while in transgenic mice there was increased expression in TBs and even higher level at BOAs. The results of qRT-PCR of MMP7 were confirmed by IHC (Figure $3 \mathrm{c}$ and $\mathrm{d}$ ).

To validate the expression of MMP7 in humans, we performed IHC on seven lung cancer resection specimens with

Table 1 The spatial expression patterns of MMP and TIMP mRNAs in the mouse lung using LCM

\begin{tabular}{|c|c|c|c|c|c|}
\hline \multirow[t]{2}{*}{ MMP2 } & $\mathrm{BL}$ & 3 & $3.34 \pm 3.34$ & $14.31 \pm 3.63$ & 0.793 \\
\hline & $\mathrm{BOA}$ & 3 & & $37.06 \pm 8.87^{a}$ & 0.023 \\
\hline \multirow[t]{2}{*}{ MMP7 } & $B L$ & 3 & $0 \pm 0$ & $0 \pm 0$ & 1.000 \\
\hline & $\mathrm{BOA}$ & 3 & & $219.96 \pm 32.71^{\mathrm{a}}$ & 0.000 \\
\hline \multirow[t]{3}{*}{ MMP9 } & $B L$ & 3 & $396.49 \pm 211.62$ & $145.08 \pm 48.30$ & 0.543 \\
\hline & TB & 3 & $57.44 \pm 57.43$ & $134.22 \pm 40.74$ & 0.981 \\
\hline & $\mathrm{BOA}$ & 3 & & $671.55 \pm 152.95^{a}$ & 0.013 \\
\hline MMP13 & $\mathrm{BL}$ & 3 & $25.36 \pm 12.66$ & $0 \pm 0$ & 0.111 \\
\hline & TB & 3 & $56.52 \pm 8.14$ & $24.08 \pm 3.27$ & 0.039 \\
\hline & $\mathrm{BOA}$ & 3 & & $27.19 \pm 9.10^{\mathrm{a}}$ & 0.066 \\
\hline \multirow[t]{3}{*}{ TIMP2 } & $\mathrm{BL}$ & 3 & $4.76 \pm 1.61$ & $6.03 \pm 0.82$ & 0.976 \\
\hline & TB & 3 & $7.58 \pm 0.85$ & $3.27 \pm 0.37$ & 0.439 \\
\hline & $\mathrm{BOA}$ & 3 & & $6.09 \pm 2.41^{\mathrm{a}}$ & 0.968 \\
\hline
\end{tabular}

$n=$ number of animals; $P$-value of levels in transgenic mice compared with WT animals.

${ }^{\mathrm{a}} \mathrm{BOAs}$ were compared with WT TBs. 
BOA lesions. Most intense staining was seen in bronchi and glands. In the peripheral lung eight out of $16(50 \%)$ BL revealed weak to moderate level of MMP7 immunoreactivity in $\geq 50 \%$ of scattered epithelial cells, while 14 out of $20(70 \%)$ BOA lesions and six out of seven (86\%) tumors were positive (Figure $3 \mathrm{e}$ and $\mathrm{f}$ ). Staining was predominantly cytoplasmic. Human BOAs were negative for ASH1 and NE markers (Supplementary Figure S1).

Akt pathway is important for cell survival in many tissues. Specifically, it is relevant for lung carcinogenesis, as it is activated early in the process both in the airway and alveolar compartments. ${ }^{36}$ In the transgenic mouse, we detected elevated levels of phosphorylated Akt (p-Akt), which is the active form of Akt and the activated mammalian target of rapamycin, phosphorylated mTOR (p-mTOR), which is its downstream target gene. IHC and WB analysis of LCM samples gave comparable results (Figure $3 g$ and $\mathrm{j}$ ).

Taken together, examination of gene expression in transgenic mouse lungs revealed region-specific patterns, which included increased levels of MMP7 in TBs and BOAs.

\section{Silencing of hASH1 Suppresses Proliferation and Increases Apoptosis in Human Lung Cancer Cells}

To establish a functional correlation between hASH1, cellular growth and apoptosis, we used two well-characterized human lung cancer cell lines that express hASH1 constitutively (Figure 4). We transfected DMS53 (SCLC) and H727 (carcinoid) cell lines with hASH1 siRNAs. Marked hASH1 knockdown was achieved by three different siRNA sequences, which by $72 \mathrm{~h}$ resulted in significantly increased apoptosis and decreased growth at 5 days (Figure 4). The inhibition of growth was more pronounced in the SCLC line DMS53, which also revealed higher levels of apoptosis than the carcinoid cell line H727 following hASH1 siRNA treatment (Figure $4 \mathrm{c}-\mathrm{f}$ ). Increased apoptosis induced by siRNA was confirmed by WB, which showed enhanced levels of cleaved poly(ADP-ribose) polymerase (PARP) in DMS53 cell line. In H727 WB was not sensitive enough to detect cleaved PARP because of lower apoptotic rates (2-6\%) (Figure 4e and f). Notably, by WB hASH1 knockdown was also associated with decreased expression of c-Myb and MMP7, which is consistent with our in vivo results. However, there was no change in $\mathrm{p}$-Akt, $\mathrm{p}-\mathrm{mTOR}$ or Bcl-2 expression (Figure $4 \mathrm{a}$ and b).

\section{Forced Expression of hASH1 in Immortalized Human Airway Epithelial Cells Enhances Growth by Suppressing Apoptosis Without NE Differentiation}

Further evidence for the functional role of hASH1 came from the experiments where this gene was transfected into immortalized human airway epithelial BEAS-2B cells, which normally do not express hASH1 (Figure 5). Following selection, two clones that showed stable expression of hASH1 by IHC, qRT-PCR and WB analyses were chosen for further examination (Figure $5 \mathrm{a}-\mathrm{c}$ ). The clones exhibited modestly enhanced growth but a marked $50-75 \%$ decrease in apoptosis
(Figure $5 \mathrm{e}$ and $\mathrm{f}$ ). Forced expression of hASH1 in BEAS-2B also showed increased cell invasion but no change in cell migration (Figure $5 \mathrm{~g}$ and $\mathrm{h}$ ). This was associated with increased expression of p-Akt, and p-mTOR but decreased expression of active MMP7. Using Scion Software to detect the intensity we were able to demonstrate about fourfold increase of p-Akt and threefold increase of p-mTOR in both hASH1 transfected clones compared with the BEAS-2B vector-transfected control. BEAS-2B cells revealed constitutive expression of $\mathrm{Bcl}-2$ with no change by forced expression of hASH1 (Figure $5 \mathrm{c}$ and d). Forced expression of hASH1 in the lung adenocarcinoma cell line NCI-H23 also showed significantly decreased apoptosis and increased cell migration but failed to show obvious changes in cell growth. WB demonstrated that hASH1 does promote c-Myb expression in this cell line (data not shown). The NE markers neurofilament 200 (NEFT) and synaptophysin (SYN) were negative in hASH1 transfected BEAS-2B by WB while there was high expression of both markers in the SCLC cell line DMS53 (Supplementary Figure S1). It indicated that there was no NE differentiation in BEAS-2B/hASH1 cells.

\section{DISCUSSION}

Our studies reveal that constitutive expression of the bHLH transcription factor hASH1 in epithelial progenitors (Clara cells) results in the expansion of the cell population. It leads to remodeling of the peripheral lung through activation of genes implicated in carcinogenesis. Interestingly, airway cells at the critical anatomical convergence of two lung compartments, BL and alveoli, lose their competence to respond to pro-apoptotic signals.

One of our principal findings is that the proneural transcription factor hASH1 has a major impact on the growth of pulmonary epithelial cells. While many members of the large bHLH family of transcription factors including c-Myc, Nmyc and MyoD may play dual roles in cellular differentiation and proliferation, this is the first report on the impact of hASH1 on non-NE cells. We have previously shown that mASH1 is necessary for NE differentiation in mouse lung as knockout of this gene results in the absence of PNECs. ${ }^{2}$ However, there is no overt NE differentiation in epithelial cells that constitutively express hASH1 in the transgenic mouse. This mirrors its function in autonomic neurogenesis, as mASH1 does not restrict multipotent cells to a neuronal fate but rather promotes the committed precursors. ${ }^{10}$ In the current study, mASH1 expression is directed to the epithelial progenitor cell population of non-ciliated secretory epithelial cells (Clara cells) using the CC10 promoter.

CC10 promoter becomes active only around embryonic date (E) 17, which is later than the commitment to PNEC fate. ${ }^{13,37}$ Mouse PNECs containing $\mathrm{mASH} 1$ are visible by $\mathrm{E}$ 13.5, but distinct endodermal cell lineages that contribute to PNECs become established before the formation of the definitive lung bud at E9.0-9.5 $5^{8,38}$ (unpublished observation). Clara cells are known progenitors for themselves and 
ciliated cells, and they can rapidly repopulate damaged or denuded airway epithelium, which may contribute to their ready response to hASH1-conferred stimulus on growth. ${ }^{14,15}$

The second principal finding in the study is that hASH1 promotes $\mathrm{BOA}$, a potential premalignant lesion also found in the human lung. ${ }^{21} \mathrm{BOA}$ is a histologically distinct metaplastic lesion, where alveolar epithelium is replaced by bronchiolar (airway)-type epithelium. There are two theories on the mechanism of BOA. ${ }^{20}$ According to the first one bronchiolar epithelial cells migrate distally and repopulate the existing septa of the alveolar compartment. The second one suggests that alveolar type II cells transform into airway epithelium. Our results show that constitutive hASH1 expression leads to progressive epithelial hyperplasia in a spatial or tissuespecific manner. The highest level of proliferation occurred in the distal airways (BL and TBs) of young transgenic animals. This is in concert with the fundamental ability of peripheral mouse lung to grow postnatally. ${ }^{39}$ In contrast, the apoptotic rate peaked in TBs of the WT animals, while the rate was very low in transgenic mice. It suggests that cellular apoptosis is of major importance guarding the sharp demarcation of airway epithelium at the BADJ. Our interpretation is that hASH1 conveys resistance to apoptosis in airway epithelial cells, which leads them to populate and migrate to the alveolar compartment adjacent to the airways. This takes place independent of NE differentiation since mouse BOAs have no PNECs.

The resistance to apoptosis in vivo was associated with increased expression of the anti-apoptotic gene Bcl-2 and activation of the Akt pathway, both of which have been shown to be important in early lung carcinogenesis. ${ }^{40-43}$ $\mathrm{Bcl}-2$ protects cells from apoptosis by a variety of apoptotic stimuli, regulates cell cycle, migration and gene expression. ${ }^{44,45}$ On the other hand, signaling through the phosphatidylinositol 3-kinase (PI3-kinase) pathway results in the phosphorylation of Akt at serine 473 and/or threonine 308 . Akt then activates a series of cancer-related functions such as cell proliferation, motility, invasion and decrease of cell death in human tumors. ${ }^{46,47}$ More specifically, Akt has been shown to inactivate pro-apoptotic factors in Bcl-2 family such as BAD and (pro) caspase-9. It also contributes to cellular migration and invasiveness by stimulating secretion of MMPs. It is likely that the decrease in apoptosis at the BADJ contributes to increased numbers of bronchiolar cells that then migrate to the alveolar space through Bcl-2 and Akt-associated mechanisms.

The functional link was established using human lung cancer cell lines and immortalized bronchial epithelial cells. Many lung cancers, especially SCLCs express high levels of Bcl-2 and activated Akt. ${ }^{48,49}$ Downregulation of hASH1 by siRNAs lead to increased apoptosis which resulted in potentially compensatory increase in Bcl-2 in the pulmonary carcinoid cells, which normally express hASH1. On the other hand, enforced expression of hASH1 in the immortalized human bronchial epithelial BEAS2B cells which normally lack hASH1 was associated with increased expression of p-Akt and p-mTOR, a downstream target of Akt and significant drop in apoptosis. The results suggest that both Bcl-2 and Akt may be involved in the hASH1-induced anti-apoptotic effect, depending on the cellular context.

It is notable that suppression of ASH1 has been recently shown to induce apoptotic cell death in SCLCs by activation of caspases. ${ }^{11}$ In our study, we were able to show that the inhibition of growth and induction of apoptosis by ASH1siRNA was particularly robust in SCLC cells that demonstrated higher levels of hASH1 expression than carcinoid cells, which was confirmed by the expression of cleaved PARP, another marker of apoptotic activity. Taken together, these findings demonstrate that ASH1 may be an effective and novel cell-specific therapeutic target in lung NE carcinomas.

We noted a spatial gradient of increasing expression of MMP7 (matrilysin) towards BOA in CC10-hASH1 mouse lungs. MMP7 is a member of a multiple enzyme family, the MMPs, which have been principally associated with degradation of extracellular matrix component. ${ }^{50}$ Unlike many other MMPs, which are expressed as a host stromal response to a tumor, MMP7 is produced by tumor cells themselves at an early stage. ${ }^{34}$ This has been observed in adenomas or premalignant lesions of the intestine, stomach, prostate, breast and ovary. ${ }^{51-56}$ We observed low levels of MMP7 in normal human lung epithelial cells, while the expression increased in premalignant and neoplastic cells. Using genetically manipulated animals, a definite role for MMP7 in early tumor development has been established. Ablation of MMP7 reduced tumor formation by $67 \%$ in the multiple intestinal neoplasia (Min) mouse model of intestinal cancer. ${ }^{57}$ Conversely, overexpression of MMP7 in the mammary glands of MMTV-neu mice, a mouse model of mammary carcinogenesis, significantly accelerated tumor development. ${ }^{58}$ These studies are in concert with our observations suggesting that MMP7 may play a crucial role in formation of BOA in CC10-hASH1 mouse lungs.

It is notable that the epithelial hyperplasia especially in BL was associated with increased expression of c-Myb. c-Myb belongs to the myb family of intrinsic transcription factors involved in cell cycle regulation. Notably, in the prostate c-Myb was found to be a downstream effector of hASH1 and $\mathrm{c}-M y c .^{32,59}$ In proliferating myoblasts c-Myb binds MyoD, another basic HLH factor, and inhibits its transcriptional activity until cell-cell contacts are established, and c-Myb expression is switched off. ${ }^{60}$ Because $\mathrm{Bcl}-2$ is one of $\mathrm{c}-\mathrm{Myb}$ targets, ${ }^{61}$ it is conceivable that hASH1 may activate c-Myb, which will promote $\mathrm{Bcl}-2$ expression in the airway epithelium of transgenic mice. So c-Myb/Bcl-2 pathway may play a crucial role in hASH1-induced proliferation and antiapoptosis in airway epithelium.

While we have shown that the expression of hASH1 in vivo and in vitro is able to control apoptosis and proliferation, it became evident that the response to hASH1 is also strongly dependent on the cellular context. In vivo the micro- 


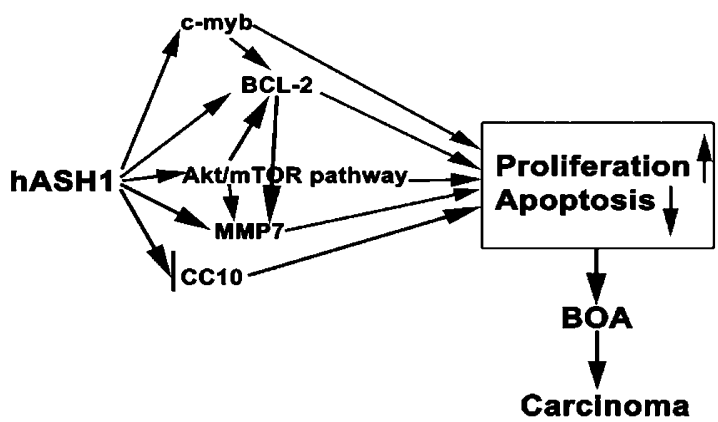

Figure 6 Schematic presentation of pathways activated by constitutive expression of $\mathrm{hASH} 1$ in pulmonary epithelium during remodeling and carcinogenesis. hASH1 may promote proliferation and resistance to apoptosis independent of NE differentiation through pathways involving Bcl-2, Akt, c-Myb, MMP7 and CC10. It also provides a mechanistic model for $\mathrm{BOA}$, a potentially premalignant lesion. We conclude that constitutive expression of hASH1 in lung epithelial progenitor cells promotes remodeling and preneoplasia of pulmonary epithelium via many of the same genes that are important for lung carcinogenesis.

environment along the airway axis from proximal towards the peripheral (BL vs $\mathrm{TB}$ or $\mathrm{BOA}$ ) lung is likely to contribute to the region-specific molecular patterns, we have observed. In vitro, the cell lines tend to be intrinsically heterogeneous. For instance, following hASH1 gene silencing in DMS53 and NCI-H727 c-Myb was decreased but we could not show that $\mathrm{Bcl}-2$ was decreased. One explanation is that $\mathrm{Bcl}-2$ is constitutively elevated and not a target gene of c-Myb in these two NE cell lines. For this reason, future studies should include direct manipulation of lung tissues to study further the molecular mechanism of BOA.

In summary, the significance of our study is two-fold. It established that hASH1 might promote proliferation and resistance to apoptosis independent of NE differentiation through pathways involving Bcl-2, Akt, c-Myb, MMP7 and $\mathrm{CC} 10$. While the role of hASH1 in human peripheral airway cell carcinogenesis remains elusive, our study provides a mechanistic model for $\mathrm{BOA}$, a potentially premalignant lesion. In other words, constitutive expression of hASH1 in lung epithelial progenitor cells promotes remodeling and preneoplasia of pulmonary epithelium via many of the same genes that are important for lung carcinogenesis (Figure 6). This is similar to human BOAs that reveal increased proliferation, progression of atypia and genetic changes associated with cancer. ${ }^{21}$ In the future it will be possible to explore ways to alter these pathways, prevent carcinogenesis and define, for the first time, critical preclinical tests for chemoprevention studies of peripheral lung carcinomas using this model.

Supplementary Information accompanies the paper on the Laboratory Investigation website (http://www.laboratoryinvestigation.org)

\section{ACKNOWLEDGEMENT}

This research was supported by the Intramural Research Program of the $\mathrm{NIH}$, National Cancer Institute. We thank the NIH Fellows Editorial Board for critically reviewing the manuscript and providing comments.
1. Jemal A, Siegel R, Ward E, et al. Cancer statistics, 2006. CA Cancer J Clin 2006;56:106-130.

2. Borges $\mathrm{M}$, Linnoila $\mathrm{Rl}$, van de Velde $\mathrm{HJ}$, et al. An achaete-scute homologue essential for neuroendocrine differentiation in the lung. Nature 1997;386:852-855.

3. Ledent V, Paquet $\mathrm{O}$, Vervoort M. Phylogenetic analysis of the human basic helix-loop-helix proteins. Genome Biol 2002;3:research0030.1research0030.18.

4. Huber K, Bruhl B, Guillemot F, et al. Development of chromaffin cells depends on MASH1 function. Development 2002;129:4729-4738.

5. Lanigan TM, DeRaad SK, Russo AF. Requirement of the MASH-1 transcription factor for neuroendocrine differentiation of thyroid C cells. J Neurobiol 1998;34:126-134.

6. Kameda Y. Mash1 is required for glomus cell formation in the mouse carotid body. Dev Biol 2005;283:128-139.

7. Linnoila Rl. Functional facets of the pulmonary neuroendocrine system. Lab Invest 2006;86:425-444.

8. Ito T, Udaka N, Yazawa T, et al. Basic helix-loop-helix transcription factors regulate the neuroendocrine differentiation of fetal mouse pulmonary epithelium. Development 2000;127:3913-3921.

9. Schuurmans C, Guillemot F. Molecular mechanisms underlying cell fate specification in the developing telencephalon. Curr Opin Neurobiol 2002;12:26-34.

10. Sommer L, Shah N, Rao M, et al. The cellular function of MASH1 in autonomic neurogenesis. Neuron 1995;15:1245-1258.

11. Osada $\mathrm{H}$, Tatematsu $\mathrm{Y}$, Yatabe $\mathrm{Y}$, et al. ASH1 gene is a specific therapeutic target for lung cancers with neuroendocrine features. Cancer Res 2005;65:10680-10685.

12. Ray MK, Magdaleno SW, Finegold MJ, et al. cis-acting elements involved in the regulation of mouse Clara cell-specific 10-kDa protein gene. In vitro and in vivo analysis. J Biol Chem 1995;270:2689-2694.

13. Margraf LR, Finegold MJ, Stanley LA, et al. Cloning and tissue-specific expression of the CDNA for the mouse Clara cell $10 \mathrm{kD}$ protein: comparison of endogenous expression to rabbit uteroglobin promoter-driven transgene expression. Am J Respir Cell Mol Biol 1993;9:231-238.

14. Brody AR, Hook GE, Cameron GS, et al. The differentiation capacity of Clara cells isolated from the lungs of rabbits. Lab Invest 1987;57: 219-229.

15. Evans MJ, Cabral-Anderson LJ, Freeman G. Role of the Clara cell in renewal of the bronchiolar epithelium. Lab Invest 1978;38: 648-653.

16. Linnoila Rl, Sahu A, Miki M, et al. Morphometric analysis of CC10hASH1 transgenic mouse lung: a model for bronchiolization of alveoli and neuroendocrine carcinoma. Exp Lung Res 2000;26:595-615.

17. Linnoila Rl, Zhao B, DeMayo JL, et al. Constitutive achaete-scute homologue-1 promotes airway dysplasia and lung neuroendocrine tumors in transgenic mice. Cancer Res 2000;60:4005-4009.

18. Giangreco A, Reynolds SD, Stripp BR. Terminal bronchioles harbor a unique airway stem cell population that localizes to the bronchoalveolar duct junction. Am J Pathol 2002;161:173-182.

19. Kim CF, Jackson EL, Woolfenden $A E$, et al. Identification of bronchioalveolar stem cells in normal lung and lung cancer. Cell 2005;121:823-835.

20. Nettesheim P, Szakal AK. Morphogenesis of alveolar bronchiolization. Lab Invest 1972;26:210-219.

21. Jensen-Taubman SM, Steinberg SM, Linnoila RI. Bronchiolization of the alveoli in lung cancer: pathology, patterns of differentiation and oncogene expression. Int J Cancer 1998;75:489-496.

22. Linnoila RI, Jensen SM, Steinberg SM, et al. Peripheral airway cell marker expression in non-small cell lung carcinoma. Association with distinct clinicopathologic features. Am J Clin Pathol 1992;97:233-243.

23. Yang Y, Zhang Z, Mukherjee AB, Linnoila RI. Increased susceptibility of mice lacking Clara cell $10-\mathrm{kDa}$ protein to lung tumorigenesis by 4-(methylnitrosamino)-1-(3-pyridyl)-1-butanone, a potent carcinogen in cigarette smoke. J Biol Chem 2004;279:29336-29340.

24. Tamaoki J, Tagaya E, Kawatani K, et al. Airway mucosal thickening and bronchial hyperresponsiveness induced by inhaled beta 2-agonist in mice. Chest 2004;126:205-212.

25. Betsuyaku T, Griffin GL, Watson MA, et al. Laser capture microdissection and real-time reverse transcriptase/polymerase chain reaction of bronchiolar epithelium after bleomycin. Am J Respir Cell Mol Biol 2001;25:278-284. 
26. Jones $M B$, Krutzsch $H$, Shu $H$, et al. Proteomic analysis and identification of new biomarkers and therapeutic targets for invasive ovarian cancer. Proteomics 2002;2:76-84.

27. Sriuranpong $V$, Borges MW, Ravi RK, et al. Notch signaling induces cell cycle arrest in small cell lung cancer cells. Cancer Res 2001;61: 3200-3205.

28. Tsurutani J, Castillo SS, Brognard J, et al. Tobacco components stimulate Akt-dependent proliferation and NF\{kappa\}B-dependent survival in lung cancer cells. Carcinogenesis 2005;26:1182-1195.

29. Westerman BA, Neijenhuis S, Poutsma A, et al. Quantitative reverse transcription-polymerase chain reaction measurement of $\mathrm{HASH} 1$ (ASCL1), a marker for small cell lung carcinomas with neuroendocrine features. Clin Cancer Res 2002;8:1082-1086.

30. Gibson UE, Heid CA, Williams PM. A novel method for real time quantitative RT-PCR. Genome Res 1996;6:995-1001.

31. Neuringer IP, Randell SH. Stem cells and repair of lung injuries. Respir Res 2004;5:6.

32. Hu $Y$, Wang $T$, Stormo GD, et al. RNA interference of achaete-scute homolog 1 in mouse prostate neuroendocrine cells reveals its gene targets and DNA binding sites. Proc Natl Acad Sci USA 2004;101:5559-5564.

33. Ramsay RG, Barton AL, Gonda TJ. Targeting c-Myb expression in human disease. Expert Opin Ther Targets 2003;7:235-248.

34. Wilson $\mathrm{CL}$, Matrisian LM. Matrilysin: an epithelial matrix metalloproteinase with potentially novel functions. Int J Biochem Cell Biol 1996;28:123-136.

35. Parks WC, Shapiro SD. Matrix metalloproteinases in lung biology. Respir Res 2001;2:10-19.

36. West KA, Linnoila IR, Belinsky SA, et al. Tobacco carcinogen-induced cellular transformation increases activation of the phosphatidylinositol 3'-kinase/Akt pathway in vitro and in vivo. Cancer Res 2004;64: 446-451.

37. Have-Opbroek AA, De Vries EC. Clara cell differentiation in the mouse: ultrastructural morphology and cytochemistry for surfactant protein $A$ and Clara cell 10 kD protein. Microsc Res Tech 1993;26:400-411.

38. Perl AK, Wert SE, Nagy A, et al. Early restriction of peripheral and proximal cell lineages during formation of the lung. Proc Natl Acad Sci USA 2002;99:10482-10487.

39. Amy RW, Bowes $\mathrm{D}$, Burri $\mathrm{PH}$, et al. Postnatal growth of the mouse lung J Anat 1977:124:131-151.

40. Ferron PE, Bagni I, Guidoboni $M$, et al. Combined and sequential expression of $\mathrm{p} 53, \mathrm{Rb}$, Ras and $\mathrm{Bcl}-2$ in bronchial preneoplastic lesions. Tumori 1997;83:587-593.

41. Tsao AS, McDonnell T, Lam S, et al. Increased phospho-AKT (Ser(473)) expression in bronchial dysplasia: implications for lung cancer prevention studies. Cancer Epidemiol Biomarkers Prev 2003;12: 660-664.

42. Massion PP, Taflan PM, Shyr Y, et al. Early involvement of the phosphatidylinositol 3-kinase/Akt pathway in lung cancer progression. Am J Respir Crit Care Med 2004:170:1088-1094.

43. Balsara BR, Pei J, Mitsuuchi $Y$, et al. Frequent activation of AKT in non-small cell lung carcinomas and preneoplastic bronchial lesions. Carcinogenesis 2004;25:2053-2059.
44. Cory S, Adams JM. The Bcl2 family: regulators of the cellular life-or-death switch. Nat Rev Cancer 2002;2:647-656.

45. Tsujimoto $\mathrm{Y}$. Cell death regulation by the $\mathrm{BCl}-2$ protein family in the mitochondria. J Cell Physiol 2003;195:158-167.

46. Testa JR, Bellacosa A. AKT plays a central role in tumorigenesis. Proc Natl Acad Sci USA 2001;98:10983-10985.

47. Okudela $\mathrm{K}$, Hayashi $\mathrm{H}$, Ito $\mathrm{T}$, et al. K-ras gene mutation enhances motility of immortalized airway cells and lung adenocarcinoma cells via Akt activation: possible contribution to non-invasive expansion of lung adenocarcinoma. Am J Pathol 2004;164:91-100.

48. Kumar BS, Huang J, Persaud $\mathrm{S}$, et al. Down-regulation of $\mathrm{BCl}-2$ is associated with cisplatin resistance in human small cell lung cancer H69 cells. Mol Cancer Ther 2004;3:327-334.

49. Tsurutani J, West KA, Sayyah J, et al. Inhibition of the phosphatidylinositol 3-kinase/Akt/mammalian target of rapamycin pathway but not the MEK/ERK pathway attenuates laminin-mediated small cell lung cancer cellular survival and resistance to imatinib mesylate or chemotherapy. Cancer Res 2005;65:8423-8432.

50. Polette M, Nawrocki-Raby B, Gilles C, et al. Tumour invasion and matrix metalloproteinases. Crit Rev Oncol Hematol 2004;49: $179-186$

51. Newell KJ, Witty JP, Rodgers WH, et al. Expression and localization of matrix-degrading metalloproteinases during colorectal tumorigenesis. Mol Carcinog 1994;10:199-206.

52. Takeuchi N, Ichikawa $Y$, Ishikawa $T$, et al. Matrilysin gene expression in sporadic and familial colorectal adenomas. Mol Carcinog 1997;19:225-229.

53. McDonnell S, Navre M, Coffey Jr RJ, et al. Expression and localization of the matrix metalloproteinase pump-Date: 1 (MMP-7) in human gastric and colon carcinomas. Mol Carcinog 1991;4:527-533.

54. Knox JD, Wolf $C$, McDaniel K, et al. Matrilysin expression in human prostate carcinoma. Mol Carcinog 1996;15:57-63.

55. Heppner KJ, Matrisian LM, Jensen RA, et al. Expression of most matrix metalloproteinase family members in breast cancer represents a tumor-induced host response. Am J Pathol 1996;149:273-282.

56. Shigemasa $\mathrm{K}$, Tanimoto $\mathrm{H}$, Sakata $\mathrm{K}$, et al. Induction of matrix metalloprotease-7 is common in mucinous ovarian tumors including early stage disease. Med Oncol 2000;17:52-58.

57. Wilson $\mathrm{CL}$, Heppner $\mathrm{KJ}$, Labosky $\mathrm{PA}$, et al. Intestinal tumorigenesis is suppressed in mice lacking the metalloproteinase matrilysin. Proc Natl Acad Sci USA 1997;94:1402-1407.

58. Rudolph-Owen LA, Chan R, Muller WJ, et al. The matrix metalloproteinase matrilysin influences early-stage mammary tumorigenesis. Cancer Res 1998;58:5500-5506.

59. Cogswell JP, Cogswell PC, Kuehl WM, et al. Mechanism of c-myc regulation by c-Myb in different cell lineages. Mol Cell Bio 1993;13:2858-2869.

60. Kaspar P, Pajer P, Sedlak D, et al. c-Myb inhibits myogenic differentiation through repression of MyoD. Exp Cell Res 2005:309:419-428.

61. Thompson MA, Rosenthal MA, Ellis SL, et al. c-Myb down-regulation is associated with human colon cell differentiation, apoptosis, and decreased Bcl-2 expression. Cancer Res 1998;58:5168-5175. 